\title{
USING IN-VEHICLE DEVICES TO EXAMINE EXPOSURE AND PATTERNS IN DRIVERS WITH PARKINSON'S DISEASE COMPARED TO AN AGE-MATCHED CONTROL GROUP
}

\author{
Alex Crizzle ${ }^{1}$, Anita Myers ${ }^{1}$, Brenda Vrkljan $^{2}$, \& Quincy Almeida ${ }^{3}$ \\ ${ }^{1}$ Department of Health Studies and Gerontology, University of Waterloo, Waterloo \\ ${ }^{2}$ Department of Rehabilitation Sciences, McMaster University, Hamilton \\ ${ }^{3}$ Sun Life Movement Disorders Research and Rehabilitation Centre (MDRC), \\ Wilfrid Laurier University, Waterloo \\ Ontario, Canada \\ Email: amcrizzl@uwaterloo.ca
}

\begin{abstract}
Summary: Symptoms associated with Parkinson's disease (PD), as well as medications, can influence safe driving. Some studies have shown that drivers with PD make more errors and may have more crashes. Although a few studies have suggested drivers with PD may self-regulate by reducing amount of driving and avoiding challenging situations, findings are based on self-report data. The purpose of this study was to objectively examine naturalistic driving exposure and patterns in drivers with PD compared to an age-matched group of healthy drivers using electronic, in-vehicle devices over a two week monitoring period. Compared to the controls, the PD group drove significantly less overall (number of trips, kilometres, duration), on weekends and at night. When adjusted for number of days of driving, the PD group still made fewer trips and drove proportionately less at night. This was the first study to examine the actual driving practices of a PD population using objective measures.
\end{abstract}

\section{INTRODUCTION}

Parkinson's disease (PD) is a progressive neurodegenerative disorder, causing motor, cognitive and visuoperceptual deficits which can impact on driving and the prevalence of PD is expected to increase in the coming years (Kontakos \& Stokes, 2002). Functional driving abilities can be impaired even in the early stages of PD (Klimkeit et al., 2009). Not surprisingly, drivers with PD have been reported to have higher crash rates (Adler et al., 2000) and perform more poorly on simulators (e.g., Stolwyk et al., 2006) and road tests (e.g., Uc et al., 2007; Wood et al., 2005). As noted in the review article by Klimkeit et al. (2009), there is a need for further research on the amount of driving by individuals with PD, the context of driving (e.g., roadways), as well as the capacity of drivers with PD to self-regulate and compensate for their functional declines.

It has been argued that crash risk may be reduced if seniors in general adopt safer driving practices, commensurate with their skills and regulate their driving to reduce task demands (Eby \& Molnar, 2009). Two studies have found that, compared to healthy older drivers, those with PD drive less (fewer km) overall, at night, in peak traffic, long distances, and are less likely to drive alone ( Adler et al., 2000; Wood et al., 2005). However, findings were based on self-report data. Studies with healthy older drivers have shown that self-estimates of driving exposure $(\mathrm{km})$ are inaccurate relative to objective measures (Huebner et al., 2006; Blanchard \& Myers, 2010), calling into question the validity of other self-report practices such as avoidance ratings. Self- 
report measures of driving are subject to recall and social desirability bias (Lajunen \& Summula, 2003). Unreliable memory is a particular concern with PD (Rizzo et al., 2010). Recent studies have shown discrepancies between self-reported and objectively measured practices in healthy older drivers (Blanchard \& Myers, 2010; Blanchard et al., 2010; Myers et al., 2011). To date, however, no studies have objectively examined driving behavior in a PD population.

The primary objective of this study was to compare the actual driving practices (exposure and patterns) of older adults with PD to a healthy, age-matched control group.

\section{METHODS}

\section{Participants}

Ethics approval was obtained from ethics boards at both the University of Waterloo and Wilfrid Laurier University (WLU). A sample of 27 drivers with PD and 20 age-matched controls, primarily from urban and suburban areas of one region of Southwestern Ontario, were assessed between October, 2009 and August, 2010. Drivers with PD were recruited through the Sun Life Financial Movement Disorders Research and Rehabilitation Centre at WLU, while the control group was recruited from clubs and recreation centers. To be eligible for the study, drivers with PD needed to have two of four cardinal symptoms (bradykinesia, resting tremor, rigidity, postural instability) and a confirmed diagnosis of PD by a neurologist. All participants had to be aged 55+, have a valid license, be the primary driver (in the case of shared vehicles), currently drive at least 3x/week and have a non-hybrid vehicle (for compatibility with the CarChip device). Exclusion criteria were: glaucoma, age-related macular degeneration, stroke, dementia, schizophrenia, untreated sleep apnea and anti-anxiety medications (and any neurological disorder for the control group).

\section{Actual Driving Behaviour}

The CarChip Pro® (Model 8226; Davis Instruments, Hayward, CA) and the Otto Driving Companion ${ }^{\circledR}$ (Model PM2626; Persen Technologies, Winnipeg, MB) were installed in each subject's vehicle for two weeks. The CarChip (see Figure 1) was installed into the vehicle's onboard diagnostic (OBDII) system, while the Otto (a small GPS device), shown in Figure 2, was mounted on the dashboard. While both devices collect similar date and time stamped information (i.e., distance travelled, duration), delayed connection to satellite signals (cold starts) and signal loss (due to overhead obstructions) can result in lost data, especially for short trips (Blanchard et al., 2010; Grengs et al., 2008). The CarChip has been shown to be more accurate in recording distance (Huebner et al., 2006), thus was used for most of the indicators. The GPS data was primarily used to examine roadways and to calculate radius or distance from home (paired with digital maps). Participants were asked to complete trip logs during the monitoring period to identify if there were other drivers of the vehicle, presence of passengers and destinations.

\section{Analysis}

Data from the CarChip and Otto were downloaded and cleaned (i.e., trips with $0.0 \mathrm{~km}$ or by drivers not in the study were removed). To determine complete trips, segments were linked by 
cross-referencing CarChip data with the trip logs and/or Otto data. Archives were accessed for daily times of sunrise/sunset and combined with the time-stamped data, used to examine instances of night driving. Variables were assessed for normality to determine appropriate use of parametric versus non-parametric analyses using both visual examination (normal probability plots, histograms, stem and leaf plots) and statistical tests (Fisher skewness and kurtosis, Kolmogrov-Smirnov and Shapiro-Wilks tests). Roadways driven were examined using the GPS data, including freeways (multi-lane, divided with speed limits greater than $90 \mathrm{~km} / \mathrm{hr}$ ) and highways (two-lane with speed limits greater than $70 \mathrm{~km} / \mathrm{hr}$ or as classified on road maps). Average radius each person drove from his/her home was calculated for each trip.
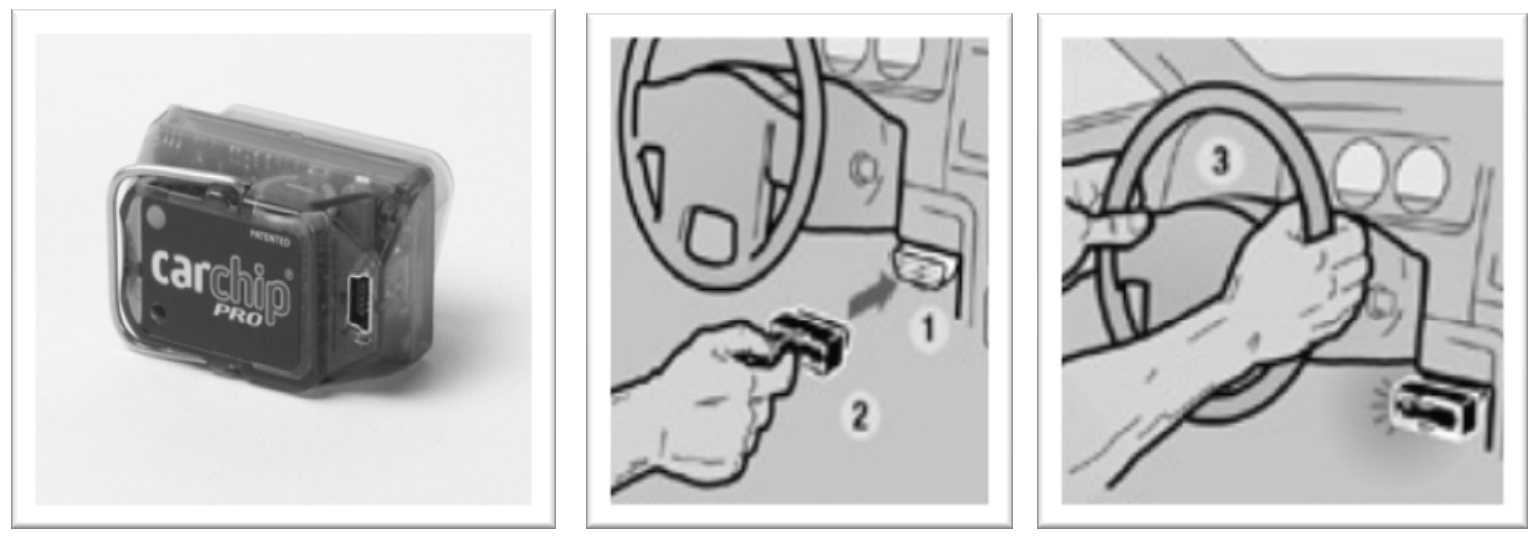

Figure 1. CarChip Pro (from Davis Instruments)
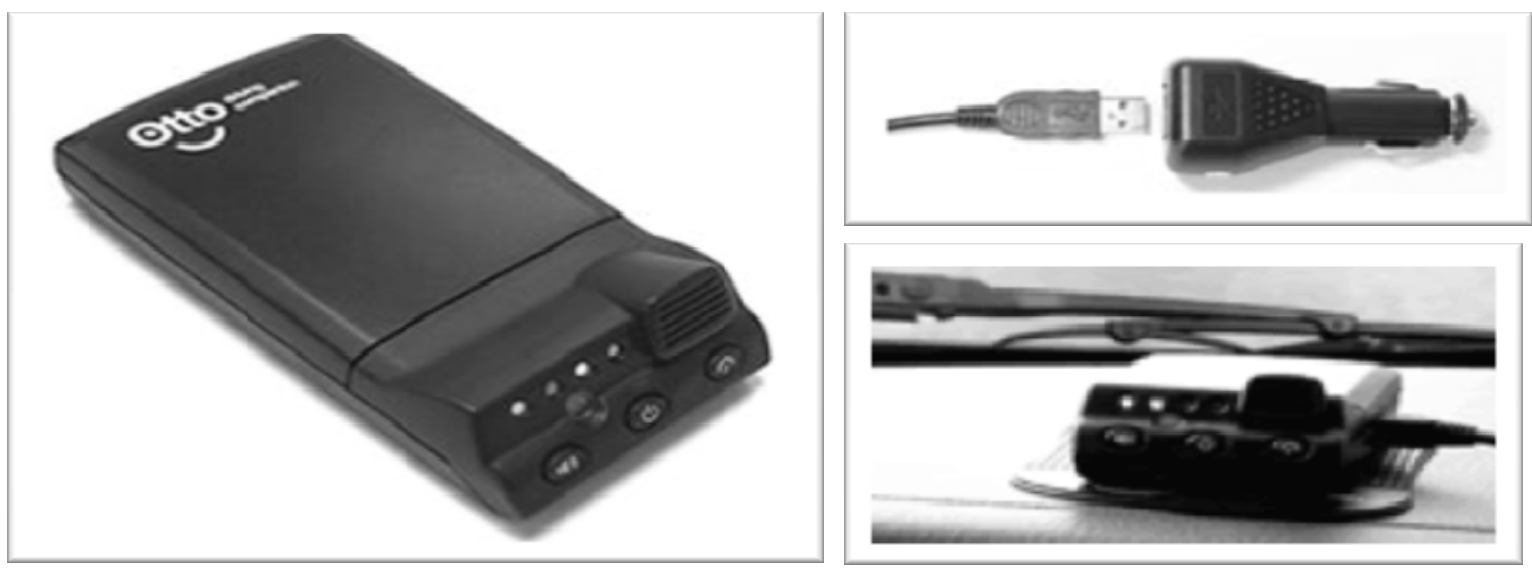

Figure 2. Otto Driving Companion (from Persen Technologies Inc.)

\section{RESULTS}

\section{Sample Characteristics}

Drivers with PD (21 men, 6 women) ranged in age from 57 to $82(\mathrm{M}=71.6$, S.D. $=6.6)$ and those in the control group (16 men, 4 women) ranged from 57 to $84(\mathrm{M}=70.6$, S.D. $=7.9)$. Most $\mathrm{PD}$ and control group drivers rated their health as good or excellent (82\% versus $100 \%)$; were college/university educated (70\% versus $75 \%)$, could walk one quarter of a mile (82\% versus $100 \%$ ) and did not require the use of a cane or walker (74\% versus $95 \%$ ). Diagnosed health 
conditions most often reported by PD and control drivers were: high blood pressure (56\% versus $50 \%$ ), arthritis, rheumatism and/or osteoporosis (44\% versus 35\%), back problems (26\% versus $10 \%)$, hearing problems (19\% versus 35\%) and sleep disorders (11\% versus $15 \%)$ and cataracts (7\% versus $20 \%)$. The majority of the sample (95\%) rated their eyesight as the same or better than most their age; only 2 PD subjects rated their eyesight as worse. A greater proportion of PD subjects (48\% versus 15\%) preferred to have a passenger, as opposed to driving alone.

\section{Driving Exposure}

Driving data for one PD participant could not be obtained as this person lost his license over the study period. For two others with missing CarChip data, Otto data were used. Three controls were missing one week of Otto data. To include these individuals in the analyses, driving data were averaged for one week. As shown in Table 1, on average, the PD group drove significantly fewer days $(z=-3.22, p=.001)$, trips $(z=-3.93, p=.001)$, stops $(z=-3.03, p=.002), \operatorname{km}(t=-$ $2.21, p=.035)$ and for shorter durations $(t=-2.08, p=.04)$ than the control group. Although not shown in Table 1, women in the PD group generally drove more than men (days, trips and $\mathrm{km}$ ) while women in the control group drove less than men. When adjusted for number of days driven, the PD group still made significantly fewer trips $(t=-2.59, p=.01)$ than controls. However, group differences concerning average distance $(\mathrm{km})$ and duration were no longer significant when adjusted by number of trips and by days.

Table 1. Average Driving Exposure by Group

\begin{tabular}{|c|c|c|c|c|c|}
\hline & $\begin{array}{c}\text { PD } \\
n=26\end{array}$ & $\begin{array}{c}\text { Control } \\
n=20\end{array}$ & & $\begin{array}{c}\text { PD } \\
n=26\end{array}$ & $\begin{array}{c}\text { Control } \\
n=20\end{array}$ \\
\hline \#Days ${ }^{a}$ & $\begin{array}{l}4.84 \pm 1.35 \\
2 \text { to } 7\end{array}$ & $\begin{array}{c}6.10 \pm .79 \\
4.5 \text { to } 7\end{array}$ & $\begin{array}{l}\text { Radius } \\
\text { (avg) }\end{array}$ & $\begin{array}{c}6.02 \pm 4.65 \\
1.99 \text { to } 21.22\end{array}$ & $\begin{array}{c}6.67 \pm 5.40 \\
1.49 \text { to } 23.09\end{array}$ \\
\hline \# Trips ${ }^{a}$ & $\begin{array}{c}6.63 \pm 2.90 \\
2 \text { to } 14\end{array}$ & $\begin{array}{l}9.89 \pm 3.27 \\
5.5 \text { to } 20.5\end{array}$ & Nights Driven ${ }^{a}$ & $\begin{array}{c}1.16 \pm .80 \\
0 \text { to } 3\end{array}$ & $\begin{array}{c}2.40 \pm 1.54 \\
0 \text { to } 5.5\end{array}$ \\
\hline \#Stops ${ }^{a}$ & $\begin{array}{c}16.25 \pm 7.61 \\
6.5 \text { to } 33\end{array}$ & $\begin{array}{c}23.88 \pm 8.22 \\
14 \text { to } 39.5\end{array}$ & Night Trips $^{\text {a }}$ & $\begin{array}{c}1.22 \pm .91 \\
0 \text { to } 4\end{array}$ & $\begin{array}{c}2.68 \pm 1.93 \\
0 \text { to } 7\end{array}$ \\
\hline Distance $(\mathrm{km})^{\mathrm{a}}$ & $\begin{array}{l}188.78 \pm 102.25 \\
60.95 \text { to } 407.9\end{array}$ & $\begin{array}{l}285.66 \pm 174.34 \\
96.05 \text { to } 686.9\end{array}$ & Night $\mathrm{Km}^{\mathrm{a}}$ & $\begin{array}{c}16.22 \pm 16.70 \\
0 \text { to } 73.45\end{array}$ & $\begin{array}{c}40.42 \pm 38.47 \\
0 \text { to } 142.7\end{array}$ \\
\hline $\begin{array}{l}\text { Duration } \\
\text { (hr:min) }^{\mathrm{a}}\end{array}$ & $\begin{array}{c}4: 59 \pm 2: 04 \\
1: 59 \text { to } 9: 14\end{array}$ & $\begin{array}{c}6: 32 \pm 2: 59 \\
3: 06 \text { to } 14: 03\end{array}$ & $\begin{array}{c}\text { Night } \\
\text { Duration } \\
\text { (min:sec) }\end{array}$ & $\begin{array}{c}25: 33 \pm 23: 30 \\
0 \text { to } 1: 41: 17\end{array}$ & $\begin{array}{c}55: 20 \pm 47: 54 \\
0 \text { to } 3: 22: 01\end{array}$ \\
\hline
\end{tabular}

Note: Values are Mean \pm SD and range; Group comparisons; independent t-tests $t(p)$ or Mann-Whitney U; ${ }^{\text {a }}$ significant group difference

\section{Driving Patterns}

Driving patterns were examined according to when (days of the week, day versus night) and where (types of roadways) people drove over the two week monitoring period. When adjusted for the number of days driven, the PD group made significantly fewer trips on weekdays $(t=-$ $2.92, p=.006)$ and drove fewer $\mathrm{km}$ on the week-end $(t=-1.98, p=.04)$ than controls. The PD group did most of their driving during the middle of the week (on Tuesdays and Thursdays); mileage was lowest on the weekend (Saturdays and Sundays).

Only three PD (11.5\%) and two control participants (10\%) did not drive at night at all over the two weeks. As shown in Table 1, on average, the PD group drove fewer nights $(t=-3.27, \mathrm{p}=$ 
.003), trips $(z=-3.07, \mathrm{p}=.002), \mathrm{km}(t=-2.43, p=.015)$ and shorter durations at night $(z=-2.35$, $p=.19)$ than controls. When adjusted for number of nights driven, group differences in average $\mathrm{km}$ and duration were no longer significant. When controlling for the number of opportunities to drive at night (based on 14 days in the monitoring period), the PD group drove proportionately less at night than controls $(\chi 2=17.7, p=.001)$. There were no group differences in the proportion of complete versus partial night trips (i.e., those either starting or ending in darkness).

Trip segments were examined by GPS data (aerial maps from Google Earth) to determine the types of roads participants travelled on over the study period. All participants drove at least once on city roads over the two weeks, over $95 \%$ of both groups drove on residential streets, and $69 \%$ of PD and $68 \%$ of controls drove on rural roads. Although not significant, fewer of the PD drivers drove on highways (77\% versus $95 \%$ ) and freeways (46\% versus $63 \%$ ) than controls.

\section{DISCUSSION}

This was the first study to objectively examine driving exposure and patterns in a sample of drivers with PD. As the data collection period extended from October, 2009 to August, 2010, an age-matched group of healthy older drivers from the same area was included to control for time of year and regional weather conditions. Seasonal and geographical factors are important to consider in driving studies, as both weather and amount of daylight have been shown to influence exposure and patterns such as night driving (Myers et al., 2011).

Overall, the findings indicate that drivers with PD appear to drive less than healthy drivers of a similar age, consistent with prior self-report findings (Adler et al., 2000; Wood et al., 2005). When adjusting for number of days driven, the PD group still made significantly fewer trips than controls. Drivers with PD appear to be doing more "trip chaining”, i.e., making more stops for shopping, errands and other purposes when they do drive. The PD group also drove proportionately less at night. Whether this is due to purposeful regulation (insight into their condition), symptoms (e.g., bradykinesia, fatigue) or other factors requires further research. Replication with much larger samples is needed to examine gender differences, as well as subtype PD drivers according to their most debilitating symptoms and medication use (Klimkeit et al., 2009).

Those who volunteered for driving studies in general tend to be more educated (Rudman et al., 2006) and our PD sample may be more active than drivers with PD in general, given the study criteria of driving at least 3x/week. Although nearly three quarters of the sample said their driving was fairly typical over the two weeks, some participants reported driving more (4 PD and 5 controls) and others less (1 PD and 2 controls). Most (94\%) said the devices did not affect their driving, however one woman with PD said she deliberately drove slower as she thought the devices were tracking her speed.

In any case, a two week monitoring period provides only a glimpse into actual driving practices. Simple electronic devices like the CarChip and Otto used in this study provide a great deal of data which is extremely complex and time consuming to cross-reference and analyze (e.g. Blanchard et al., 2010; Grengs et al., 2008). Limitations of the CarChip are that this device cannot be used in older models (prior to 1996) or hybrid vehicles (due to the alternating power 
source). Limitations of GPS devices (signal loss) are also well-known (e.g., Grengs et al., 2008). Memory capacity is an additional issue, as the devices we used have a capacity of only 300 hrs.

Ultimately, longitudinal studies are required to examine changes in driving exposure and patterns as the severity of PD progresses. Such studies require more sophisticated devices with greater memory capacity, as are being used in the five-year cohort study by Candrive researchers.

\section{ACKNOWLEDGEMENTS}

Student support for the primary author was provided by the Canadian Driving Research Initiative for Vehicular Safety in the Elderly (Candrive), the Schlegel Research Institute of Aging (RIA), the Auto 21 Network of Centres of Excellence and the Sun Life Financial Movement Disorders Research and Rehabilitation Centre.

\section{REFERENCES}

Adler, G., Rottunda, B.S., Bauer, M., \& Kushowski, M. (2000). The Older Driver with Parkinson’s Disease. Journal of Gerontological Social Work, 34(2), 39-49.

Blanchard, R.A., \& Myers, A.M. (2010). Examination of Driving comfort and self-regulatory practices in older adults using in-vehicle devices to assess natural driving patterns. Accident Analysis and Prevention, 42, 1213-1219.

Blanchard, R.A., Myers, A.M., \& Porter, M.M. (2010). Correspondence between self-reported and objective measures of driving exposure and patterns in older drivers. Accident Analysis and Prevention, 42, 523-529.

Davis Instruments. (2008). Retrieved on September 2008, from http://www.davisnet.com/drive/products/ drive_product.asp?pnum $=08226$

Eby, D.W., \& Molnar, L.J. (2009). Older adult safety and mobility: Issues and research needs. Public Works Management \& Policy, 13(4), 2009.

Grengs, J., Wang, X., Kostyniuk, L.P. (2008). Exploiting GPS data to understand driving behavior. Journal of Urban Technology, 15, 33-53.

Huebner, K., Porter, M.M., \& Marshall, S.C. (2006). Validation of an electronic device for measuring driving exposure. Traffic Injury Prevention, 7, 76-80.

Klimkeit, E.I., Bradshaw, J.L., Charlton, J., Stolwyk, R., \& Georgiou-Karistianis, N. (2009). Driving Ability in Parkinson's Disease: Current status of research. Neuroscience and Biobehavioral Reviews, 33, 223-231.

Kontakos, N., \& Stokes, J. (2000). Monograph series on age related disorders: XII. Parkinson's Disease-Recent developments and new directions. Public Health Agency of Canada, 20(3).

Lajunen, T., Summala, H. (2003). Can we trust self-reports of driving? Effects ofimpression management on driver behaviour questionnaire responses. Transportation Research Record, F6, 97-107.

Myers, A.M., Trang, A., \& Crizzle, A.M. (2011). Naturalistic Study of Winter Driving Practices by Older Men and Women: Examination of Weather, Road Conditions, Trip Purposes and Comfort. Canadian Journal on Aging, in press. 
Persen Technologies (2008). Retrieved June, 2008, from www.myottomate.com.

Rizzo, M., Uc, E.Y., Dawson, J.D., Anderson, S.W., \& Rodnitzky, R. (2010). Driving difficulties in Parkinson's disease. Movement Disorder Society, 1, S136-140.

Rudman, D., Friedland, J., Chipman, M.L., \& Sciortino, P. (2006). Holding On and Letting Go: The Perspectives of Pre-Seniors and Seniors on Driving Self-Regulation in Later Life. Canadian Journal on Aging, 25(1), 65-76.

Stolwyk, R.J., Charlton, J.L., Triggs, T.J., Iansek, R., \& Bradshaw, J.L. (2006). Neuropsychological Function and Driving Ability in People with Parkinson's Disease. Journal of Clinical and Experimental Neuropsychology, 28, 898-913.

Uc, E.Y., Rizzo, M., Anderson, S.W., Sparks, J.D., Rodnitzky, R.L., \& Dawson, J.D. (2007). Impaired navigation in drivers with Parkinson's disease. Brain, 130, 2433-2440.

Wood. J.M., Worringham, C., Kerr, G., Mallon, K., \& Silburn, P. (2005). Quantitative Assessment of Driving Performance in Parkinson's Disease. Journal of Neurology, Neurosurgery, and Psychiatry, 76, 176-180. 